\title{
Sobre Tempo e Conhecimentos Praticados na Escola de Tempo Integral
}

\author{
Lígia Martha Coimbra da Costa Coelho' \\ Lúcia Velloso Maurício"
}

UniversidadeFederal do Estado do Rio de Janeiro (UNIRIO), Rio deJaneiro/RJ-Brasil "Universidade do Estado do Rio de Janeiro (UERJ), Rio de Janeiro/RJ - Brasil

RESUMO - Sobre Tempo e Conhecimentos Praticados na Escola de Tempo Integral. Este ensaio analisa a ampliação da jornada e a natureza da educação escolar no contexto dos projetos de sociedade que configuram a escola pública de tempo integral, no Brasil. O texto estrutura-se em duas seções. A primeira reflete acerca da natureza dos conhecimentos veiculados pelas escolas que funcionam em tempo integral, a partir da relação entre os conhecimentos historicamente constituídos e os conhecimentos locais. A segunda seção discute como a articulação das atividades diversificadas compõe o conhecimento praticado pela escola, tendo em vista a inclusão social e a construção da cidadania.

Palavras-chave: Educação em Tempo Integral. Conhecimentos Praticados. Conhecimentos Historicamente Constituídos. Conhecimentos Locais.

ABSTRACT - On Time and Practiced Knowledge in Full-Time School. This essay analyzes the extension of the learning time and the nature of school education in the context of the society projects that configure the full-time public school in Brazil. The text is structured in two sections. The first one reflects on the nature of the knowledge provided by full-time schools, from the relationship between the historically formed knowledge and local knowledge. The second section discusses how the articulation of diversified activities makes up the knowledge practiced by the school, in order to achieve social inclusion and citizenship.

Keywords: Full-Time Education. Practiced Knowledge. Historically Constituted Knowledge. Local Knowledge.

Educação \& Realidade, Porto Alegre, v. 41, n. 4, p. 1095-1112, out./dez. 2016.1095 http://dx.doi.org/10.1590/2175-623660673 
Sobre Tempo e Conhecimentos Praticados na Escola de Tempo Integral

\section{Introdução}

O século XXI tem se apresentado pródigo para com as questões relacionadas à ampliação do tempo escolar no Brasil. Por pródigo, estamos nos referindo à profusão legal e acadêmica de produções oriundas dessa temática emergente e não, necessariamente, aos seus rumos político-filosóficos e epistemológicos, bem como às perspectivas de análise que se configuram/desenham no panorama que baliza essas questões. Em outras palavras, não obrigatoriamente o fato de serem produzidos textos - oficiais, acadêmicos, ou de outra natureza -, nos deve levar à conclusão de que temos, hoje, um acúmulo qualitativo de reflexões acerca da ampliação da jornada escolar para o tempo integral que efetive uma educação de qualidade ${ }^{1}$ no país.

Caminhando mais concretamente sobre esse chão, é preciso escolher as veredas pelas quais andaremos, sob pena de superficializarmos e/ou fragilizarmos uma discussão que pode ser abordada por diferentes vieses. Nessa perspectiva, falamos da educação na escola pública que vem implementando o tempo integral e da forma como os conhecimentos, que são parte da natureza dessa instituição formal de ensino, são desenvolvidos para serem apropriados por aqueles que a frequentam: os alunos das classes populares.

Dito de outra forma, pensamos que um debate que se impõe é o de refletir acerca dos conhecimentos que são trazidos para a escola científicos, estéticos, éticos, corporais - e de como esses conhecimentos podem ser trabalhados em um tempo alargado que, efetivamente, construa práticas mais emancipadoras, tanto para esses conhecimentos entendidos como duros, quanto para aqueles relacionados a uma cidadania mais partícipe. Assim, pretendemos discutir o que vimos denominando de conhecimentos praticados nas escolas de tempo integral, na perspectiva de construção de lógicas diferenciadas de trabalho pedagógico com esses mesmos conhecimentos e outros que a eles aderem, no sentido de ampliar horizontes socioculturais e político-pedagógicos.

Esse limite que nos impomos nos traz algumas questões: ao falarmos de educação escolar pública há, obviamente, projetos de sociedade em disputa por esse espaço. Como esses projetos entendem esses conhecimentos trabalhados pela escola? Que articulações podem ser pensadas, no sentido de redesenhar a relação entre estes conhecimentos, sua apropriação e possibilidade de emancipação, principalmente quando essa instituição trabalha em tempo integral?

Essas questões construíram o norte deste artigo, que pretende analisar a ampliação da jornada e a natureza da educação escolar no contexto dos projetos de sociedade que configuram a escola pública de tempo integral, no Brasil. Mais especificamente, optamos por refletir sobre a relação que esse espaço formal de ensino estabelece com os conhecimentos historicamente constituídos - universais ou locais, e sua apropriação pelas classes populares que nele se encontram.

1096 Educação \& Realidade, Porto Alegre, v. 41, n. 4, p. 1095-1112, out./dez. 2016. 
Para tanto, estruturamos o ensaio em duas seções. Na primeira, buscamos refletir acerca da natureza dos conhecimentos veiculados pelas escolas, sua(s) configuração(ões) e articulação(ões), no sentido de levar esse debate mais amplo à instituição escolar que funciona em tempo integral. A segunda seção pretende pensar sobre a relação entre os desenhos desse tempo integral escolar, em direção aos projetos de sociedade em que estes se constituem - situação que a contemporaneidade vem apresentando, sem que estejam claros os contornos político-ideológicos dessa relação.

Nesse sentido, nos perguntamos inicialmente: o que entendemos por conhecimentos praticados, quando estes se materializam em um espaço formal de ensino - a escola de tempo integral?

\section{Escola Pública e(m) Tempo Integral: quais conhecimentos?}

Ao pensarmos sobre a natureza da escola pública - desde que esta se constituiu, na modernidade - sem dúvida alguma o conhecimento emerge como um de seus pilares: seria ela o lócus privilegiado para a apropriação dos conhecimentos que foram formando a civilização humana ao longo dos tempos. A partir dessa apropriação, outro pilar se faria complementar: a possibilidade de que todos os cidadãos a ele tivessem acesso; afinal, "os homens nascem e são livres e iguais em direitos. As distinções sociais só podem fundamentar-se na utilidade comum", como prescreve a Declaração dos Direitos do Homem e do Cidadão, desde os idos da Revolução Francesa.

Trazendo essa reflexão para os dias atuais, constatamos que a ideia de igualdade no acesso à escola pública, assim como aos conhecimentos por ela veiculados ainda se faz presente, pelo menos no imaginário daqueles que a procuram como alunos, responsáveis ou como professores, gestores ou funcionários. Como reforçam Masschelein e Simons (2014, p. 40), "[...] a escola sempre significa conhecimento em prol do conhecimento, e a isso chamamos de estudo". Em outras palavras, podemos inferir que os pesquisadores belgas, ao defenderem a escola, confirmam a importância dos conhecimentos que essa instituição apresenta como possível desencadeadora de ações e/ou reflexões capazes de construir outros tantos conhecimentos e, portanto, capazes de fazer avançar - ou, quem sabe, fazer regredir - o mundo e a humanidade.

Partimos, assim, do pressuposto de que a escola (pública) tem os conhecimentos como um de seus pilares mais significativos e, nesse sentido, cabe-nos, em um primeiro momento desta seção, buscar a atualização do pressuposto, ou seja, podemos afirmar, na contemporaneidade, que a adesão à escola se pauta pelo conhecimento a que se referem Masschelein e Simons?

Verificamos, hoje em dia, que as sociedades contemporâneas vêm, paulatinamente, construindo outra lógica na sua relação com o

Educação \& Realidade, Porto Alegre, v. 41, n. 4, p. 1095-1112, out./dez. 2016.1097 
Sobre Tempo e Conhecimentos Praticados na Escola de Tempo Integral

conhecimento, notadamente, o que denominamos de conhecimentos em sua relação com a escola. Essa lógica se materializa em práticas pedagógicas que os trabalham de formas diferenciadas, ou seja, desenhos outros que trazem à baila como os conhecimentos são praticados.

Um dos caminhos que essa lógica contemporânea apresenta é a necessidade de que esses conhecimentos se revistam de condições sociais de uso - que sejam úteis na vida. Esta perspectiva considera a possibilidade de incorporação do capital cultural a que Bourdieu se refere, em vários de seus escritos (2014), para além daquele constituído no ambiente doméstico. Saber utilizar um caixa eletrônico, por exemplo, não pode mais ser atividade apenas para alguns nas sociedades atuais, e isto é conhecimento que pode ser adquirido na escola, a partir da criação de diferentes situações pedagógicas que levem a esse conhecimento útil.

No entanto, dentro ainda desse contexto, nos perguntamos se o fato de revestir os conhecimentos veiculados pela escola de suas condições sociais de uso significa deixar de lado sua natureza primeira, qual seja, se dar a conhecer, mostrar-se em sua cientificidade, em sua estética. Em outras palavras, se os conhecimentos têm uma linguagem própria, que também é conhecimento, de que conhecimentos estamos falando, em um contexto escolar com tempo integral? Como articulá-los, de modo a construir um eixo norteador que impulsione a apropriação desses conhecimentos pelos alunos das classes populares?

Bernard Lahire (2008), em pesquisa sobre o sucesso escolar nos meios populares, buscava compreender que diferenças poderiam explicar as variações na escolaridade das crianças. Alertava, logo de início, que se afastava de "qualquer ideia de evolução cognitiva natural e universal, comum ao conjunto de crianças de uma mesma faixa etária" (Lahire, 2008, p. 19). Apontava que fracassos ${ }^{2}$ escolares podiam ser entendidos como "casos de solidão dos alunos no universo escolar" (Lahire, 2008, p. 19), tendo em vista a dissonância entre as relações sociais familiares na qual essas crianças foram socializadas e as formas escolares de relações sociais com as quais deviam conviver. Segundo o autor:

Realmente, eles não possuem as disposições, os procedimentos cognitivos e comportamentais que lhes possibilitem responder adequadamente às exigências e injunções escolares, e estão portanto sozinhos e como que alheios diante das exigências escolares. Quando voltam para casa, trazem um problema (escolar) que a constelação de pessoas que os cerca não pode ajuda-los a resolver: carregam, sozinhos, problemas insolúveis (Lahire, 2008, p. 19).

Em busca das diferenças que explicariam as variações na escolaridade das crianças das classes populares, Lahire elencou cinco temas que considerou pertinentes às configurações familiares das 27 crianças pesquisadas: as formas familiares da cultura escrita; as condições e disposições econômicas; a ordem moral doméstica; as formas de autoridade familiar e as formas familiares de investimento pedagógico. Para 
este ensaio, privilegiamos a discussão da cultura escrita e do investimento pedagógico, tendo em vista, segundo nossa leitura, a grande repercussão que ocasionam na possibilidade de adesão à cultura escolar, condição relevante para as reflexões que pretendemos fazer, no âmbito da escola de tempo integral e dos conhecimentos praticados nesse contexto. Ademais, os conhecimentos advindos da cultura escrita são, de certo modo, raiz para todos os demais conhecimentos que se veiculam na escola e, também, na sociedade.

Paulo Freire, quando aprofunda seu conceito de leitura de mundo, afirma que "[...] a leitura de mundo precede a leitura da palavra [...]. Linguagem e realidade se prendem dinamicamente" (Freire, 2006, p. 11). Nessa perspectiva, Freire apresenta a leitura da palavra escrita como articuladora dos conhecimentos, saberes e situações reais que, constituindo o mundo, precisam ser traduzidos de alguma forma pelos sujeitos que vivem em uma mesma sociedade. Ora, sendo a escola o espaço formal de encontro dos conhecimentos, caberia à língua a tarefa de veicular esse encontro. Funcionando a escola em tempo integral, como o tempo ampliado pode auxiliar esse trabalho, de encontro de conhecimentos, a partir da articulação com a língua escrita?

Lahire participa da compreensão de que a leitura pode conduzir a práticas de grande importância para o sucesso escolar. Entretanto, chama a atenção para o fato de que a prática de leitura no ambiente familiar pode levar a experiências positivas ou negativas. Em caso de experiência positiva, para além do hábito de leitura, ela pode gerar outro efeito indireto, mas poderoso: o distanciamento entre o falante e sua prática. De modo semelhante, a incorporação de elementos como o calendário ou a agenda tem a função de objetivar o tempo, instrumentos que contribuem para relações sociais mais planejadas e menos espontâneas como ocorrem no meio familiar. Segundo Lahire "As práticas de escrita e gráfica introduzem uma distância entre o sujeito falante e sua linguagem e lhe dão os meios de dominar simbolicamente o que até então dominava de forma prática: a linguagem, o espaço e o tempo" (Lahire, 2008, p. 23).

Assim, o aluno que vive em meio doméstico temporalmente ordenado incorpora espontaneamente métodos de organização e estruturas cognitivas ordenadas, que o predispõem a participar espontaneamente da lógica escolar. A criança criada na cultura oral precisa realizar um esforço de linguagem e de ordenação do tempo e de suas ações para integrar-se a essa mesma lógica. Essa criança tanto pode rejeitar esta nova ordem, como desenvolver um processo de aproximação. Como fazer esta passagem?

Uma das possibilidades, dolorosa, seria a imersão em instituição que concentre em torno da criança, por longos períodos, esta nova lógica, as chamadas instituições totais, como os internatos e seminários. A outra seria, tendo como condição a consciência deste processo de transição pela escola e seus agentes, oferecer à criança um rito de passagem,

Educação \& Realidade, Porto Alegre, v. 41, n. 4, p. 1095-1112, out./dez. 2016.1099 
Sobre Tempo e Conhecimentos Praticados na Escola de Tempo Integral

no sentido de construir ambientes, atividades, desafios em que a opção pelo novo ordenamento seja gratificante. Neste sentido, a extensão do tempo de permanência neste novo contexto - as atividades escolares é um fator de grande contribuição a este processo. Concordando com Lahire, há inúmeras situações em que as crianças são levadas a construir disposições, conhecimentos e habilidades em situações organizadas por adultos em que não há intenção de transmissão de conhecimento. A jornada diária ampliada oportuniza várias situações como estas, nos pátios, nos refeitórios, em jogos e mesmo - e por que não? - nas aulas.

É importante observar, em experiências de escola de tempo integral ou de ampliação da jornada escolar já desenvolvidas, ou em desenvolvimento, no Brasil, se há indícios de que o projeto, em sua estrutura, comporta esta dimensão de passagem de uma cultura oral para a adesão a uma cultura escrita, ou seja, se é possível identificar ações ou propostas de atividades que indiquem, entre outros elementos, a importância do trabalho com a língua materna e a língua padrão, assim como a maneira com que este trabalho é realizado. Vamos citar três exemplos: um da década de 1980, desenvolvido em proposta estadual de escola de tempo integral no estado do Rio de Janeiro; outro, já no século XXI, em proposta municipal de ampliação da jornada escolar, no município de Sobral, no Ceará, e também o Programa Mais Educação.

Nos Centros Integrados de Educação Pública (CIEPs), nas décadas de 80 e 90 do século XX, a linguagem e a comunicação estavam no centro das reflexões do seu projeto pedagógico. Compreendia-se que a escrita, embora de indiscutível necessidade no mundo moderno, é apenas uma das modalidades da língua, e que a supremacia da linguagem oral é inquestionável. Há crianças que chegam à escola com experiências múltiplas e variadas de leitura e escrita. São crianças que já reconhecem o valor social da leitura e do saber que a escola se propõe a ensinar. Outras crianças chegam à escola sem descobrir para que serve ler ou escrever. Cabe à escola oferecer condições às crianças das classes populares de se apoderarem das formas linguísticas que lhes permitam sua inserção na sociedade (Maurício; Rangel, 1995).

Tendo em vista esta compreensão, formularam-se alguns princípios que nortearam o trabalho pedagógico para os alunos dos anos iniciais dos CIEPs (Maurício; Rangel, 1995, p. 50-51), a saber:

- A aprendizagem da leitura e da escrita se inicia antes do ingresso da criança na escola.

- A criança aprende a linguagem escrita através da formação de conceitos.

- A aprendizagem da leitura e da escrita é um ato construído socialmente.

- O leitor/escritor se constitui através da interação com a escrita social.

1100 Educação \& Realidade, Porto Alegre, v. 41, n. 4, p. 1095-1112, out./dez. 2016. 
Neste sentido, se vivemos numa cultura letrada e urbana, presente em quase todas as situações cotidianas, cabe à escola, no início da escolarização, incentivar a criança a mostrar o que já aprendeu e a organizar estratégias para que ela desenvolva este saber. Neste processo, a criança vai formular hipóteses sobre a língua escrita e o professor deve estar atento ao que a criança quis representar com sua escrita espontânea. Como é um processo coletivo, que se dá por meio de várias interações, os trabalhos em duplas ou grupos favorecem as relações interpessoais, por meio dos quais as crianças vão incorporando e apreendendo, no grupo, a função social da língua oral e escrita. Estas reflexões constituíam a base da proposta de prática pedagógica dos CIEPs, dando ampla dimensão ao trabalho com a linguagem e ampliando a consciência do professor sobre sua responsabilidade de promover a interação no espaço escolar. Segundo Darcy Ribeiro, as aulas de linguagem deveriam ser priorizadas, no sentido de oferecer mais tempo para que o aluno se familiarizasse com a língua padrão falada e escrita pelos professores e que, inicialmente, parecia estranha ao aluno (Ribeiro, 1995).

Outro aspecto que pode ser destacado é o fato de que na proposta organizacional dos $\mathrm{CIEPs}^{3}$, as turmas de $2^{\circ}$ segmento $^{4}$, que tinham aula com docentes especialistas, tinham também como professor de referência exatamente o de língua, que coordenava os demais (Ribeiro, 1986). Neste sentido, era atribuída ao trabalho com a língua a função de agregar, orientar a construção do conjunto de saberes. Naquela época, a respeito do tema, Brandão (1989), apesar de sua crítica ao programa dos CIEPs, reconheceu que sua implantação levantou algumas questões pertinentes, entre as quais citou a proposta do ensino da língua como eixo interdisciplinar.

Pode-se dizer que o Programa Mais Educação, que tem por objetivo a ampliação da jornada escolar no contraturno, implantado pelo governo federal desde 2008, também revela sua preocupação com a linguagem. Entre os macrocampos disponibilizados para que as escolas optem por oficinas a serem oferecidas aos alunos participantes, estão o de Educomunicação, que envolve atividades de jornal escolar; rádio escolar e histórias em quadrinhos que têm a língua como eixo, seja escrita, oral ou a associação de ambas. A atividade de leitura está inserida no macrocampo de Cultura e Artes, além das línguas estrangeiras e do letramento inseridos no Acompanhamento Pedagógico.

Em certo sentido podemos reconhecer, ainda, na experiência de Sobral, no Ceará, uma proposta organizacional que também coloca o trabalho com a língua como eixo da proposta de ampliação da jornada escolar. O Programa de Jornada Ampliada Escola Viva é um projeto desenvolvido com recursos da prefeitura de Sobral, em todas as escolas municipais. Originou-se de outro anterior, que oferecia diversas atividades artísticas, mas que não eram articuladas entre si. A integração com o projeto federal Segundo Tempo, com atividades esportivas, é desejável, mas varia de acordo com a escola. São oferecidas no outro 
Sobre Tempo e Conhecimentos Praticados na Escola de Tempo Integral

turno, pelo menos 3 horas de atividades diárias de ampliação de jornada, com música, dança, contação de história, capoeira, xadrez, artes visuais, teatro. A secretaria municipal de educação disponibiliza carga horária de professores proporcional ao número de alunos inscritos nas atividades propostas pela escola, que indica o profissional a ser contratado, de acordo com um perfil sugerido pela Secretaria.

O projeto anterior tinha como prioridade a alfabetização no $2^{\circ}$ ano, para recuperar 7 mil alunos com defasagem idade-série, mas com atividades atrativas. Talvez devido a esta origem, o programa atual tenha estabelecido a leitura como eixo central para integrar o trabalho, atribuindo caráter obrigatório ao oferecimento de contação de histórias, diferentemente das outras atividades. A leitura perpassa a música, o teatro, a dança, nos dois segmentos do Ensino Fundamental. Assim, em todas as escolas há o agente de leitura, que tem de ser formado em pedagogia ou letras, ou estar no final do curso. Elege-se, entre as diversas linguagens, um professor articulador, que em geral é o agente de leitura, com carga horária de 8 horas por dia para exercer a função de coordenar as atividades. Os professores da ampliação da jornada participam do planejamento mensal da escola, mas têm carga horária própria para seu planejamento e para seu processo formativo, que é único para todas as linguagens.

Entretanto, há um aspecto a ser mencionado. Todas as escolas municipais contam com atividades de reforço escolar, que ocorrem no contraturno, mas não integram o projeto de ampliação da jornada, por mais que o aluno que a frequente permaneça o dia inteiro na escola. A secretaria de educação disponibiliza professores para o reforço, além daqueles contratados para ampliação da jornada e para substituição eventual de professores. A atividade de reforço é obrigatória para o aluno, em oposição às atividades de ampliação da jornada. A coordenadora do projeto acredita que a jornada ampliada colabora com os resultados de aprendizagem, tendo em vista a participação do aluno no teatro, na leitura, na dança, na música, no olhar dele sobre a escola, o conhecimento que ele vai adquirindo. Porém, um aluno pode deixar de frequentar as atividades da jornada ampliada para priorizar o reforço.

O fato do reforço escolar não fazer parte do Programa de Jornada Ampliada Escola Viva, a nosso ver, é revelador de diferentes concepções de trabalho com os conhecimentos, consideração enfatizada pelas naturezas diversas das duas formas de extensão da jornada - uma obrigatória e outra optativa. Com certeza, a obrigatoriedade do reforço está associada a um rigoroso controle exercido por meio de diversas avaliações externas - municipal, estadual e federal - que dizem respeito à função estrita da escola. O reforço também desenvolve atividades de língua portuguesa, mas seu foco não está na leitura, como a proposta de contação de histórias, atividade que favorece a aproximação entre a cultura oral e escrita, sinalizada por Lahire. O que se percebe, pela diferente forma de procedimentos envolvendo as atividades obrigató-

1102 Educação \& Realidade, Porto Alegre, v. 41, n. 4, p. 1095-1112, out./dez. 2016. 
rias ou eletivas que ampliam a jornada escolar, é que há uma disputa de concepções de conhecimento no trabalho pedagógico.

Esta disputa de concepções de como trabalhar para propiciar apropriação de conhecimentos também se revela em outros aspectos. Tanto no município de Sobral como no município de Eusébio (CE), a distribuição de espaços para o desenvolvimento de atividades de ampliação de jornada privilegiava os conhecimentos estritamente curriculares, ou seja, as aulas de reforço, seja de língua portuguesa ou matemática, e aconteciam em sala de aula; já as atividades mais próximas das áreas artísticas, podiam se desenvolver em qualquer espaço - no pátio, em tendas, em puxadinhos, embaixo de árvores etc. Ter atividades pedagógicas ao ar livre sempre pode ser muito agradável. Entretanto, quando elas só ocorrem com atividades de um tipo de natureza e não de outra, pode-se supor que se trata de uma concepção diferente de trabalho com os conhecimentos.

Gostaríamos de incluir, para além dos exemplos que apresentamos de trabalho com a língua, outro indício de aproximação entre tradição oral e escrita por meio do trabalho com a cultura local. Além da língua materna, muitas outras linguagens compõem a cultura com a qual uma comunidade constrói suas representações e cria identidades. Era proposta do CIEP “[...] integrar a cultura da escola com a cultura da comunidade, fazendo-as interagir fecundamente” (Ribeiro, 1995, p. 22). Para viabilizá-la, foi criada a função do animador cultural, artista local cujo compromisso era relacionar os anseios, valores e manifestações culturais da comunidade ao processo pedagógico escolar por meio de um fazer criativo, expresso numa variedade de linguagens. Segundo Cecília Conde (1995, p. 92), coordenadora da Animação Cultural:

Normalmente vinculado à educação não formal, o artista [...] ao trazer para o espaço escolar sua vivência de trabalho com a manipulação do real e do imaginário, da emoção e da sensibilidade, está apto a promover o resgate dos referenciais culturais mais próximos dos alunos como ponto de partida para um diálogo com a cultura universal.

Essa compreensão - de que o resgate dos referenciais culturais dos alunos é ponto de partida para um diálogo com a cultura universal - é, em nosso entendimento, uma pedra de toque para que, em uma escola de tempo integral, os alunos das classes populares se apropriem desses conhecimentos tidos como mais formais (pertencentes à cultura universal) de modo a se transformarem em cidadãos de direito e de fato. Em outras palavras, não basta - como muito bem evidencia Paulo Freire - partir da realidade dos alunos: é preciso ultrapassá-la, para que ocorra a apropriação dos conhecimentos universais. E a prática com a língua pode fazer a diferença, neste contexto, como evidenciam as experiências apresentadas.

Educação \& Realidade, Porto Alegre, v. 41, n. 4, p. 1095-1112, out./dez. 2016. 
Sobre Tempo e Conhecimentos Praticados na Escola de Tempo Integral

Passamos agora para o segundo fator, que privilegiamos entre os cinco apontados por Lahire como possíveis indícios explicativos de sucesso escolar, as formas familiares de investimento pedagógico. Para que a escola cumpra sua função de promover o acesso ao conhecimento universal pelas crianças que atende, incluindo aqueles de utilidade para a vida cotidiana imediata, ela precisa conhecer que representações a comunidade escolar tem da própria instituição e do conhecimento. Uma escola com maior disponibilidade de tempo tem a vantagem de poder usá-lo para identificar que expectativas desperta nos seus usuários. Entretanto, estas expectativas podem revelar que o tempo maior pode ser visto positivamente ou negativamente.

Bourdieu (2014), ao discutir a transmissão do capital cultural de uma geração para outra, alerta que as atitudes das diferentes classes sociais a respeito da escola e das possibilidades que ela implica, em grande parte, expressam os valores de sua posição social. Suas aspirações são definidas pelas condições objetivas da categoria social à qual pertencem, "[...] que excluem a possibilidade de desejar o impossível" (Bourdieu, 2014, p. 52). Acrescenta que estas mesmas condições objetivas influenciam também a atitude das crianças em relação à escola, mais especificamente na adesão a seus valores e suas normas. No caso das classes populares, elas desenvolvem um senso prático do que é possível alcançar. Nogueira e Nogueira $(2004$, p. 72$)$ sintetizam o pensamento de Bourdieu a esse respeito: "[...] o investimento no mercado escolar tenderia a oferecer um retorno baixo, incerto e a longo prazo". Por outro lado, os autores afirmam que a cultura escolar é socialmente reconhecida como legítima, como universalmente válida.

Diante do exposto acima, conclui-se que a adesão aos valores e normas escolares não é automática. É verdade que, com a universalização do acesso ao ensino fundamental, esta questão não costuma ser levantada. Naturaliza-se que todas as crianças devem ser matriculadas na escola e que esta instituição segue procedimentos justos e válidos para todos - as crianças vão à escola para aprender.

No caso da ampliação do tempo de permanência diária na escola, que não é obrigatória, os procedimentos passam a ser questionados, tanto o tempo, como o que se faz com ele durante o dia. É necessário tanto tempo para aprender? Optar ou não pela ampliação do tempo implica a adesão a esta proposta de escola e aos procedimentos que ela preconiza. Vale a pena um investimento maior de tempo no conhecimento que esta escola se propõe a veicular? Este conhecimento vai propiciar uma inserção social diferente da que a escola de meio período oferece? Ou a ampliação do tempo só se justifica para outra função escolar, que não seja promover o conhecimento?

Em artigo sobre a relação da família com a escola de tempo ampliado, Cavaliere, Coelho e Mauricio (2013) assinalaram a diferença de adesão à escola por parte dos pais em função dos contextos em que vivem. No caso de escolas rurais, este processo é mais complexo, tendo

1104 Educação \& Realidade, Porto Alegre, v. 41, n. 4, p. 1095-1112, out./dez. 2016. 
em vista a maior incidência de utilização do tempo da criança para o trabalho doméstico ou para a lavoura. Entretanto, quando há adesão, ela é mais efetiva, pois a escola assume função de referência social e cultural, gerando relação de confiança nos profissionais da escola, que sentem a valorização do seu trabalho pela comunidade. Assim, pode-se dizer que no ambiente rural, o conhecimento desempenha papel destacado no processo de adesão.

Já nas regiões metropolitanas, a adesão à jornada ampliada é mais comum, porém o que se destaca é a função de proteção que a escola desempenha em relação aos alunos. As autoras inferem que o deslocamento do sentido educacional para o assistencial agrava-se quando a ampliação da jornada se dá de forma precária, desarticulando as atividades de ensino. Registram que a preocupação do uso maior do tempo com a aprendizagem aparece no discurso dos pais. Concluindo, inferem ainda que a adesão à ampliação da jornada escolar depende do sentido atribuído à função deste aumento de tempo. Na sociedade atual - e mais especificamente, nas regiões urbanas e mais populosas - só eventualmente esta função pode ser atribuída ao conhecimento.

Essas considerações trazidas por Cavaliere, Coelho e Maurício (2013) nos auxiliam na construção de algumas indagações em relação ao problema que originou este ensaio: se a adesão à escola, pelas classes populares, não leva necessariamente em consideração os conhecimentos que esta instituição promove, qual a função do conhecimento na escola? Por que ampliar a jornada escolar, se sua natureza primeira - promover os conhecimentos - não se constitui como fundamento articulador de sua existência para aqueles que a ela recorrem? Como os projetos de sociedade têm compreendido esses conhecimentos, quando se debruçam sobre as questões relativas à educação escolar e, mais especificamente, à ampliação de sua jornada?

Essas perguntas encaminham outras questões, de cunho mais amplo: dos anos 1990 para cá, a escola ainda é vista como possibilidade de transformação, ou serão outros os caminhos que ela vem percorrendo? Nesse caso, que caminhos podem ser trilhados quando essas escolas são de tempo integral?

\section{Projetos de Escola em Tempo Integral, Projetos de Sociedade?}

As indagações que fecham o último parágrafo da seção anterior nos encaminham para um patamar da discussão que pode ser iniciado a partir de outro questionamento: se temos como pressuposto que a função da escola (pública) modifica-se de acordo com os tempos e/ ou espaços em que esta se inscreve, que projetos de sociedade estarão (en/in) formando a escola pública brasileira, hoje, mais especificamente aquela que busca ampliar sua jornada em direção ao tempo integral?

Educação \& Realidade, Porto Alegre, v. 41, n. 4, p. 1095-1112, out./dez. 2016. 1105 
Sobre Tempo e Conhecimentos Praticados na Escola de Tempo Integral

Para nos auxiliar na construção de argumentos que, minimamente, deem conta de responder provisoriamente a tantas perguntas que até aqui apresentamos, trazemos três autores ao convívio deste ensaio. De certa forma, a tríade ao discutir as questões da desigualdade e escola pública, as funções da escola pública contemporânea, no Brasil e, ainda, as concepções de tempo integral, fortalecem nossas premissas iniciais e dão base à reflexão que é nosso objeto - a relação da escola pública em tempo integral com os conhecimentos veiculados por ela. São eles Algebaile (2009); Libâneo (2012; 2015) e Cavaliere (2009).

A leitura da obra de Algebaile (2009) é bastante significativa na compreensão dos processos que vêm encaminhando a escola pública a uma ampliação para menos. De modo bastante sintético podemos dizer que a autora, ao analisar a crise da escola brasileira, argumenta que a expansão da oferta educacional para todos levou à busca por mínimos em educação, entre eles, o tempo de escolarização $0^{5}$; concomitantemente, houve um "[...] robustecimento - a utilização da escola para fins não propriamente educacionais" (Algebaile, 2009, p. 329), ou seja, seu uso para além das funções que, historicamente, lhe foram imputadas. Ainda segundo a pesquisadora, esse robustecimento não implica, necessariamente, melhorias estruturais e/ou político-pedagógicas para essa instituição formal de ensino.

Essa situação evidenciada por Algebaile nos possibilita inferir que, contemporaneamente, entre os fundamentos da crise por que passa a escola pública brasileira, podemos encontrar esse robustecimento, essa ampliação para menos, uma vez que "[...] as novas tarefas que migram para ela não representam expansão efetiva da educação escolar [...] apenas mais coisas por meio da escola, [...] em detrimento do tempo, espaço, recursos e energias que deveriam estar a serviço do conhecimento" (Algebaile, 2009, p. 329). A partir do texto de Algebaile, nos perguntamos se a escola pública de tempo integral tem igualmente ampliado esses serviços não propriamente dedicados à sua função político-pedagógica, em detrimento de trabalhos escolares a serviço da apropriação de conhecimentos significativos para a formação do cidadão brasileiro do século XXI.

Parece-nos que a resposta afirmativa a essa questão é a que mais procede, tendo em vista algumas experiências isoladas e projetos que vêm sendo implantados e implementados em instâncias subnacionais e, mais especificamente, um programa indutor, criado pelo governo federal, no bojo do Programa de Desenvolvimento da Educação (PDE): estamos nos referindo ao Programa Mais Educação (PME) ${ }^{6}$. Neste contexto específico - o do PME -, podemos dizer que aqueles conhecimentos historicamente constituídos, mesmo estando presentes no espaço escolar, não se apresentam como eixo articulador das atividades socioeducativas que são desenvolvidas no contraturno, o que, a nosso ver, caracterizaria uma secundarização dessa natureza da escola.

1106 Educação \& Realidade, Porto Alegre, v. 41, n. 4, p. 1095-1112, out./dez. 2016. 
Já o artigo de Cavaliere afirma que "[...] a escola fundamental brasileira, especialmente aquela voltada para as classes populares, sempre foi uma escola minimalista, [...] de poucas horas diárias, pouco espaço e poucos profissionais" (Cavaliere, 2009, p. 51). De certo modo, tal constatação vem ao encontro das palavras de Algebaile, no sentido da ampliação para menos. Em relação à escola de tempo integral, traz-nos a mesma inquietação - a de ampliarmos, igualmente, as desigualdades intraescolares, na medida em que, por exemplo, sejam oferecidas as mesmas atividades no contraturno ${ }^{7}$ para algumas crianças e não para todos os alunos de uma mesma escola.

Ao elaborar sua exposição acerca das atuais propostas de ampliação do tempo diário de permanência das crianças na escola, a autora nos apresenta dois formatos organizacionais, por meio dos quais essa ampliação vem se configurando no país. Segundo Cavaliere, temos uma vertente que "[...] tende a investir em mudanças no interior das unidades escolares e [...] oferecer condições compatíveis com a presença de alunos e professores em turno integral", e outra, que "[...] tende a articular instituições e projetos da sociedade que ofereçam atividades aos alunos no turno alternativo às aulas, não necessariamente no espaço escolar, mas preferencialmente fora dele" (Cavaliere, 2009, p. 52). A primeira vertente, a autora denomina como escolas de tempo integral: já a segunda, identifica como alunos em tempo integral.

Ora, no que tange ao debate que vimos empreendendo, as duas vertentes apresentadas por Cavaliere nos fornecem elementos bastante significativos para levarmos adiante a reflexão sobre os conhecimentos e o tempo integral nas escolas. Se uma proposta ou experiência municipal/escolar amplia a jornada para o tempo integral, optar pelo formato do aluno em tempo integral significa, muito provavelmente, levar mais em consideração alguns dos serviços suplementares a que Algebaile se referiu, em seu estudo. Em outras palavras, significa não priorizar a natureza primeira da escola na construção e busca pela apropriação de conhecimentos, uma vez que, nesse modelo, (i) nem todos os alunos estão em tempo integral e (ii) as atividades socioeducativas, trabalhadas no contraturno escolar, acabam por gerar uma falsa oposição entre a escola do estudo e a escola da brincadeira.

É preciso deixar claro que, com os argumentos apresentados no parágrafo anterior, não estamos deixando de considerar possíveis desenhos curriculares que alguns municípios vêm tentando apresentar, a partir da criatividade e luta por uma escola em tempo integral mais justa. Nessa perspectiva, nosso olhar se pauta por um conjunto de experiências e projetos que vêm sendo viabilizados país afora, em que as duas vertentes apresentadas por Cavaliere emergem como formas de organização das escolas que funcionam em tempo integral.

Assim, podemos dizer que as experiências e propostas a que nos referimos - estejam no formato alunos em tempo integral ou de escolas de tempo integral - materializam práticas diversas. Em pesquisas de 
Sobre Tempo e Conhecimentos Praticados na Escola de Tempo Integral

campo, percebem-se as angústias oriundas de docentes que se sentem mais compromissados com a qualidade que deve ser atribuída ao tempo ampliado; de outros, que nem sempre apreendem as possíveis mudanças advindas do tempo integral no cotidiano da escola; principalmente, percebem-se questionamentos acerca do papel dos conhecimentos trabalhados nesse tempo a mais ${ }^{8}$. É neste sentido que trazemos à reflexão dois artigos de Libâneo.

No primeiro artigo, divulgado em 2012, o autor trabalha com os conceitos de escola do conhecimento e de escola do acolhimento social. Em 2015, utilizando argumentação semelhante, Libâneo se reporta à escola de tempo integral, utilizando os termos acolhimento social e ensino-aprendizagem. Nos dois trabalhos - com predominância no primeiro - o pesquisador busca caracterizar o dualismo que ainda se mantém na escola pública brasileira, qual seja, uma escola do conhecimento para os ricos e uma escola do acolhimento social para os pobres.

As duas dimensões apresentadas dão lugar a uma discussão mais centrada na realidade da escola de tempo integral. Em síntese, neste último trabalho, o autor afirma que o tempo integral não é necessário se "[...] as políticas educacionais que caracterizam a escola como mero lugar de integração e acolhimento social, incluindo nesse rol as escolas de tempo integral, colocarem em segundo plano a formação cultural e científica dos alunos" (Libâneo, 2015, p. 297). Em outras palavras, Libâneo reforça que "[...] uma escola que só cuida da proteção social, priva os alunos do acesso aos conhecimentos e com isso provoca formas de exclusão social dentro da escola, antecipando a exclusão social na sociedade" (Libâneo, 2015, p. 298). No entanto, nos perguntamos: será que o tempo integral escolar está obrigatoriamente vinculado ao acolhimento social? Não existirão propostas que, mesmo com um olhar para a proteção integral, têm como eixo os conhecimentos universais, articulados às realidades circundantes? Pesquisas já citadas neste ensaio relataram experiências neste sentido ${ }^{9}$.

Conforme discorremos até o momento, os conhecimentos universais - sua veiculação e apropriação pelas crianças das classes populares - são o pilar de uma escola pública que se pretende justa. Nessa perspectiva, destacam-se as formas diferenciadas que esse tempo pode criar para que as crianças realmente se apropriem do conhecimento historicamente construído. No entanto, nem todas as propostas de ampliação da jornada têm esse pressuposto como base: algumas experiências e projetos que vêm se desenvolvendo no Brasil, contemporaneamente, elegeram a proteção integral como eixo norteador, colocando em segundo plano aquele pilar a que nos referimos.

Ora, a que projeto de sociedade atende uma escola pública que amplia sua jornada escolar visando à proteção integral em primeiro plano, sem resgatar os conhecimentos praticados na(s) sociedade(s) integrados e articulados - como objetivo primeiro? Podemos dizer que os conhecimentos nela praticados respondem a esta questão?

1108 Educação \& Realidade, Porto Alegre, v. 41, n. 4, p. 1095-1112, out./dez. 2016. 


\section{Considerações (Nunca) Finais}

É preciso deixar claro que entendemos os conhecimentos universais, historicamente constituídos e veiculados pela escola, como necessários e imprescindíveis à emancipação das classes populares: com eles, essa emancipação não é totalmente garantida; sem eles, estamos levando as crianças dessas classes a uma inclusão excludente, utilizando expressão de Kuenzer (2005) ${ }^{10}$. Enfatizamos que os conhecimentos universais incluem também todos os saberes práticos requeridos para a vida em sociedade no século XXI, assim como todas as linguagens expressivas e artísticas que revelam compreensões próprias de fenômenos naturais e sociais.

Quando discutimos as formas de veicular esses conhecimentos nas escolas de tempo integral, na primeira seção deste ensaio, buscamos apresentar os conhecimentos da cultura escrita, a língua, como eixo articulador dos demais conhecimentos. Também procuramos mostrar que esses conhecimentos necessitam aportar na cultura popular, sob pena de se mostrarem dissociados da realidade das crianças a quem se destinam e por quem precisam ser apropriados. Ora, um trabalho de tal envergadura pode ser viabilizado em uma escola pública cujo tempo, ampliado, possibilite a criação de atividades diversificadas, prazerosas, sem, contudo, perder o rigor de sua cientificidade, de sua estética, enfim, o centro da natureza desses mesmos conhecimentos.

Para tanto, trouxemos ao convívio deste ensaio algumas experiências de tempo integral que buscaram resgatar esses princípios. A proposta dos CIEPs, no estado do Rio de Janeiro, foi uma dessas experiências, em que o eixo norteador da língua construiu identidades com os conhecimentos universais (Ribeiro, 1986). A experiência do município de Sobral, bem mais recente, deixa claro que, quando os conhecimentos universais são entremeados pela(s) cultura(s) local(is), sua apropriação se dá dentro de outra lógica - a lógica da necessidade dessa articulação. Quanto ao Programa Mais Educação, indicamos que, de certa forma, houve uma preocupação com a(s) língua(gens) em alguns macrocampos, revelando "[...] a valorização das experiências históricas das escolas de tempo integral como inspiradoras da educação integral na contemporaneidade" (Brasil, 2010).

A tessitura de atividades diversificadas que a escola de tempo integral pode oferecer, reunindo os conhecimentos universais, historicamente constituídos, e aqueles da cultura local, vai revelar os conhecimentos praticados por ela, na busca da inclusão das crianças no contexto da sociedade em que vivem, possibilitando-lhes acessar e contribuir com toda a atividade humana que aquela cultura construiu.

Para que tal compromisso possa acontecer - com qualidade - essa escola de tempo ampliado precisa concentrar seus esforços nesse sentido. Quando, ao contrário, o compromisso primeiro evidencia a prote-

Educação \& Realidade, Porto Alegre, v. 41, n. 4, p. 1095-1112, out./dez. 2016. 1109 
Sobre Tempo e Conhecimentos Praticados na Escola de Tempo Integral

ção integral da criança, outro projeto de sociedade está em curso. Não aquele que possibilita a emancipação, mas o que contém vários elementos que, ao incluírem, levam à exclusão.

Recebido em 06 de dezembro de 2015 Aprovado em 30 de junho de 2016

\section{Notas}

1 Temos clareza quanto à ausência de consenso no que tange à discussão sobre qualidade na educação brasileira. Nessa perspectiva, ler Dourado e Oliveira (2009) e Estevão (2013), entre outros autores que discutem essa relação.

2 O autor, ao longo desta obra, sempre se refere a fracasso e sucesso entre aspas. Para este ensaio, optamos por utilizar itálico para qualquer destaque, inclusive o apresentado, relacionado a Lahire (2008).

3 Implantados através do I Programa Especial de Educação (I PEE), em 1985 e 1986.

4 Hoje, anos finais do ensino fundamental.

5 Para Algebaile, o termo tempo de escolarização comporta vários aspectos, entre eles, o número de horas de atividade escolar e os mínimos fixados para a jornada escolar diária, situações que afetam nossa discussão sobre a ampliação da jornada escolar para o tempo integral.

6 O Programa de Desenvolvimento da Educação (PDE) foi criado em abril de 2007. Constituiu-se por mais de 40 ações, incluindo entre elas o Programa Mais Educação (PME), que "visa fomentar a educação integral de crianças, adolescentes e jovens, por meio do apoio a atividades socioeducativas no contraturno escolar" (Brasil, 2007).

7 Estamos nos referindo a experiências de ampliação do tempo escolar que dividem as atividades em turno (atividades curriculares) e contraturno (outras atividades de expansão do horário escolar).

8 Vários estudos vêm sendo divulgados nesse sentido, incluindo entre eles, teses e dissertações. A título de exemplo consultar Mól (2015).

9 Experiências como as dos municípios de Petrópolis e Mesquita (Rio de Janeiro), de Russas (Ceará) e São Paulo (São Paulo) são alguns exemplos. Ver Lima e Carmo (2013) e Ardito (2013).

10 Kuenzer não utiliza a expressão para caracterizar questões relativas à nossa temática. No entanto, consideramos que há uma aproximação entre a perspectiva de inclusão excludente utilizada pela autora e a argumentação que apresentamos.

\section{Referências}

ALGEBAILE, Eveline. Escola Pública e Pobreza no Brasil: a ampliação para menos. Rio de Janeiro: FAPERJ; Lamparina, 2009.

ARDITO, Lilian Barone Vieira. A Escola em Tempo Integral e a Qualidade da Educação Pública: relato de uma experiência de educação integral na cidade de São Paulo. In: COELHO, Lígia Martha Coimbra da Costa (Org.). Educação Integral: história, políticas e práticas. Rio de Janeiro: Rovelle, 2013. P. 185-201.

1110 Educação \& Realidade, Porto Alegre, v. 41, n. 4, p. 1095-1112, out./dez. 2016. 
BRASIL. Portaria Normativa Interministerial n. 17, de 24 de abril de 2007. Institui o Programa Mais Educação que visa fomentar a educação integral de crianças, adolescentes e jovens, por meio do apoio a atividades socioeducativas no contraturno escolar. Diário Oficial [República Federativa do Brasil], Brasília, DF, 26 abr. 2007.

BRASIL. Decreto n. 7083, de 27 de janeiro de 2010. Dispõe sobre o Programa Mais Educação. Diário Oficial [da República Federativa do Brasil], Brasília, DF, 27 jan. 2010. Ed. Extra.

BOURDIEU, Pierre. Escritos de Educação. Petrópolis: Vozes, 2014.

BRANDÃO, Zaia. A Escola de $1^{\circ}$ Grau em Tempo Integral: as lições da prática. Educação e Sociedade, Campinas, n. 32, p. 116-129, 1989.

CAVALIERE, Ana Maria; COELHO, Lígia Martha; MAURÍCIO, Lúcia Velloso. Implicações da Ampliação do Tempo Escolar nas Relações entre Família e Escola. In: ROMANELLI, Geraldo; NOGUEIRA, Maria Alice; ZAGO, Nadir. Família \& Escola: novas perspectivas de análise. Petrópolis: Editora Vozes, 2013. P. 257-277.

CAVALIERE, Ana Maria Villela. Escolas de Tempo Integral Versus Alunos em Tempo Integral. In: MAURÍCIO, Lúcia Velloso. Em Aberto, Brasília, v. 22, n. 80, p. 51-64, abr. 2009.

CONDE, Cecília. Animação Cultural. In: Carta 15: o novo livro dos Cieps. Brasília: Senado Federal, 1995.

DECLARAÇÃO dos Direitos do Homem e do Cidadão. 2015. Disponível em: $<$ http://www.direitoshumanos.usp.br/index.php/Documentos-anteriores-\%C3\%A0-cria\%C3\%A7\%C3\%A3o-da-Sociedade-das-Na\%C3\%A7\%C3\%B5es-at\%C3\%A9-1919/declaracao-de-direitos-do-homem-e-do-cidadao-1789.html> Acesso em: 22 nov. 2015.

DOURADO, Luis Fernandes; OLIVEIRA, João Ferreira. A Qualidade na Educação: perspectivas e desafios. Cadernos Cedes, Campinas, v. 29, n. 78, p. 201-215, maio/ago. 2009.

ESTÊVÃO, Carlos Vilar. A Qualidade da Educação: suas implicações na política e na gestão pedagógica. Revista Brasileira de Política e Administração da Educação, Goiânia, v. 29, n. 1, p. 15-26, jan./abr. 2013.

FREIRE, Paulo. A Importância do Ato de Ler. 47. ed. São Paulo: Cortez, 2006.

KUENZER, Acacia. Exclusão Includente e Inclusão Excludente: a nova forma de dualidade estrutural que objetiva as novas relações entre educação e trabalho. In: SAVIANI, Dermeval; SANFELICE, José Luiz; LOMBARDI, José Claudinei (Org.). Capitalismo, Trabalho e Educação. 3 ed. Campinas: Autores Associados, 2005. P. 77-96.

LAHIRE, Bernard. Sucesso Escolar nos Meios Populares: as razões do improvável. São Paulo: Editora Ática, 2008.

LIBÂNEO, José Carlos. O Dualismo Perverso da Escola Pública Brasileira: escola do conhecimento para os ricos, escola do acolhimento social para os pobres. Educação e Pesquisa, São Paulo, v. 38, n. 1, p. 13-28, 2012.

LIBÂNEO, José Carlos. Escola de Tempo Integral em Questão: lugar de acolhimento social ou de ensino-aprendizagem? In: BARRA, Valdeniza Maria Lopes (Org.). Educação: ensino, espaço e tempo na escola de tempo integral. Goiânia: UFG, 2015. P. 257-308.

LIMA, Valdeney; CARMO, Lindalva Pereira. Ampliação da Jornada Escolar como Política de Educação: respostas do Município de Russas à questão. In: COELHO,

Educação \& Realidade, Porto Alegre, v. 41, n. 4, p. 1095-1112, out./dez. 2016. 
Sobre Tempo e Conhecimentos Praticados na Escola de Tempo Integral

Lígia Martha Coimbra da Costa (Org.). Educação Integral: história, políticas e práticas. Rio de Janeiro: Rovelle, 2013. P. 97-115.

MARQUES, Luciana Pacheco et al. A Educação em Tempo Integral no Município de Juiz de Fora. In: COELHO, Lígia Martha Coimbra da Costa (Org.). Educação Integral em Tempo Integral: estudos e experiências em processo. Petrópolis: DP et Alii, FAPERJ, 2009. P. 167-187.

MASSCHELEIN, Jan; SIMONS, Maarten. Em Defesa da Escola: uma questão pública. Belo Horizonte: Autêntica Editora, 2014.

MAURÍCIO, Lúcia Velloso; RANGEL, Carmen Maria. A pedagogia dos CIEPs. Carta 15: o novo livro dos CIEPs, Brasília: Senado Federal, 1995.

MÓL, Saraa César. Programa Mais Educação: mais de qual educação? 2015. 185 f. Dissertação (Mestrado em Educação) - Programa de Pós-Graduação em Educação, Processos Socioeducativos e Práticas Escolares, Universidade Federal de São João del Rey, São João del Rey, 2015.

NOGUEIRA, Maria Alice; NOGUEIRA, Cláudio Marques Martins. Bourdieu e a Educação. Belo Horizonte: Editora Autêntica, 2004.

RIBEIRO, Darcy. O Livro dos Cieps. Rio de Janeiro: Bloch Editores, 1986.

RIBEIRO, Darcy. Balanço Crítico de Uma Experiência Educacional. Carta 15: o novo livro dos Cieps. Brasília: Senado Federal, 1995.

SILVA, Bruno Adriano Rodrigues da. A Terceira Via e as Políticas Públicas de Educação Integral: sobre a organização escola/comunidade no Programa Bairro-Escola. In: COELHO, Lígia Martha Coimbra da Costa (Org.). Educação Integral em Tempo Integral: estudos e experiências em processo. Petrópolis: DP et Alii, FAPERJ, 2009. P. 127-144.

Lígia Martha Coimbra da Costa Coelho é professora do quadro permanente do Programa de Pós-Graduação em Educação da Universidade Federal do Estado do Rio de Janeiro (UNIRIO) e coordenadora do Núcleo de Estudos-Tempos, Espaços e Educação Integral (NEEPHI).

E-mail: ligiamartha25@outlook.com

Lúcia Velloso Maurício é professora associada do Programa de Pós-Graduação em Educação da Universidade do Estado do Rio de Janeiro (UERJ) Processos Formativos e Desigualdades Sociais e da Faculdade de Formação de Professores.

E-mail: luciavelloso.uerj@gmail.com

1112 Educação \& Realidade, Porto Alegre, v. 41, n. 4, p. 1095-1112, out./dez. 2016. 